\section{Intraoperative problem during surgery for Chiari malformation}

To the Editor:

I read with interest the paper by Williams et al. ${ }^{1}$ who discussed Chiari Type I malformation and postoperative respiratory failure. The authors note that the surgical procedure proceeded uneventfully. I recently provided anesthesia care for a similar case except that the procedure was not uneventful.

An obese but otherwise healthy anesthetized female was positioned in the prone position on bolsters and the head stabilized. She had had surgery for this condition $14 \mathrm{yr}$ before but her symptoms had recurred, necessitating a revision.

The procedure was uneventful until the dura was incised to explore the fourth ventricle. Cerebrospinal fluid poured out and all monitors developed flat lines. No retractor was in place compressing the brain stem but some change had occurred to affect the vital centres. Atropine was administered immediately. A stretcher was prepared so that she could be turned supine. Fortunately, the heart rate returned after about a 20 -sec interval. With a small dose of ephedrine the heart rate returned to normal and the blood pressure rose to acceptable levels. The patient was carefully monitored postoperatively and had no sequelae from the bout of asystole.

It was a valuable experience for the operating room staff because the first indication of a problem was the silence of the oximeter. There was no ECG, pulse oxymeter trace nor $\mathrm{CO}_{2}$ trace, but only the flashing red light and alarm indicating asystole.

This case demonstrates again that surgery, especially involving the posterior fossa and areas around the brain stem, requires constant attention.

Gordon R. Sellery MD FRCPC

London, Ontario

Reference

1 Williams DL, Umedaly H, Martin IL, Boulton A

Chiari type I malformation and postoperative respiratory failure. Can J Anesth 2000; 47: 1220-3.

\section{An aid to correct positioning of the ProSeal laryngeal mask}

The ProSeal laryngeal mask airway (PLMA; Laryngeal Mask Company, Henley-on-Thames, UK) is a new device developed with a modified cuff intended to

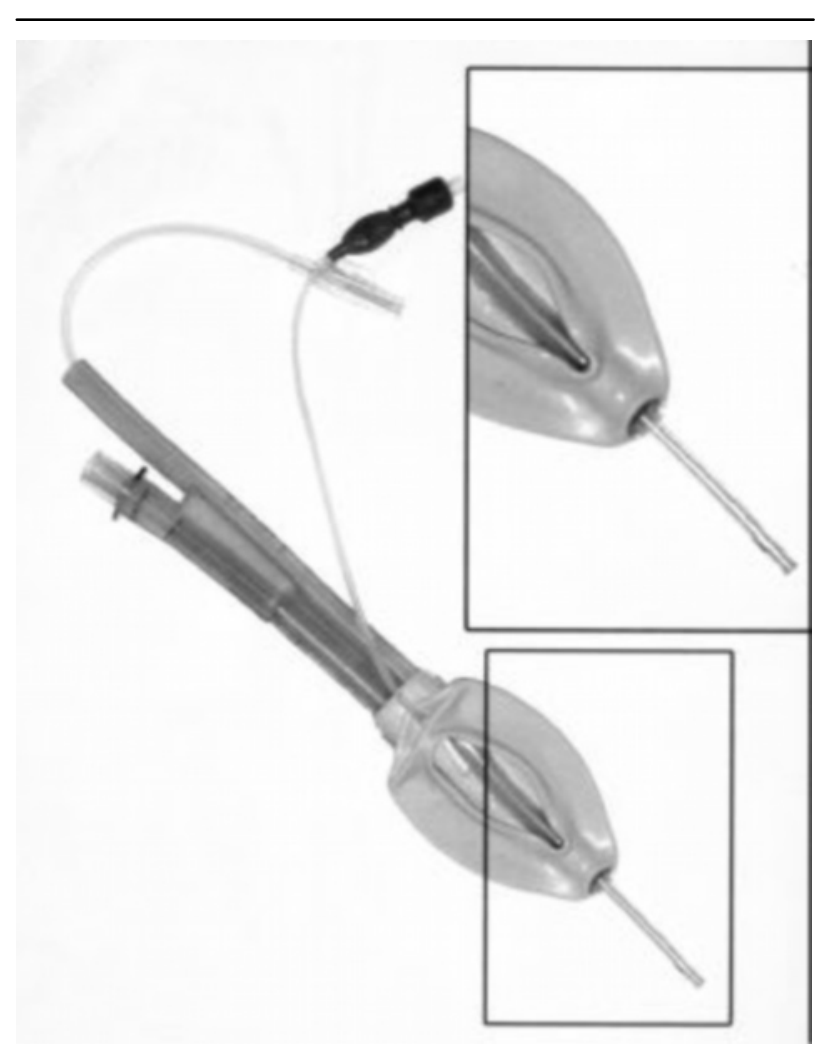

FIGURE PLMA with the aspiration catheter protruding at the end of the drainage tube.

improve the seal, and a drainage tube designed to prevent aspiration by providing a bypass channel for regurgitated gastric content. ${ }^{1,2}$ Although not mandatory, the drainage tube also offers the opportunity to pass a gastric tube through it. The insertion of the gastric tube is generally easy and reliable if the PLMA is positioned properly. ${ }^{2}$ We recently encountered a case in which an aspiration catheter could not be inserted, and corrected the problem with a simple manoeuver. After inducing anesthesia and paralysis in a 74-yr-old female scheduled for elective laparoscopic cholecystectomy, a size 4 PLMA was inserted easily and provided a satisfactory airway with a seal over $30 \mathrm{~cm} \mathrm{H}_{2} 0$ in the anesthesia circuit. Surprisingly, the attempt to insert a lubricated size $14 \mathrm{~F}$ aspiration catheter met with strong resistance inside the drainage tube. The PLMA was removed and reinserted with equal ease, after verifying the patency of the drainage tube. Again, even if the PLMA provided an excellent airway, it proved impossible to pass the aspiration catheter. We then presumed that the tip of the PLMA, where the opening of the drainage tube is located, was somehow 
kinked during insertion. We elected to reinsert the PLMA, but we allowed the aspiration catheter to protrude 4 to $5 \mathrm{~cm}$ at the end of the drainage tube during insertion (Figure). The aspiration catheter acted as a guide, directing itself and the tip of the mask towards the upper esophageal sphincter. The catheter was easily advanced in the stomach where gastric fluid was aspirated. Subsequently, the catheter was removed and reinserted successfully, demonstrating that the PLMA and its drainage tube were correctly positioned, without obstruction.

\section{Pierre Drolet MD}

Michel Girard MD

Montréal, Québec

\section{References}

1 Brimacombe J, Keller C The ProSeal laryngeal mask airway: a randomized, crossover study with the standard laryngeal mask airway in paralyzed, anesthetized patients. Anesthesiology 2000; 93: 104-9.

2 Brain AI, Verghese C, Strube PJ. The LMA 'ProSeal'-a laryngeal mask with an oesophageal vent. Br J Anaesth 2000; 84: 650-4.

\section{Prediction of difficult intubation: are we talking about the same thing?}

To the Editor:

Preoperative screening to identify those patients in whom tracheal intubation could be difficult or impos-

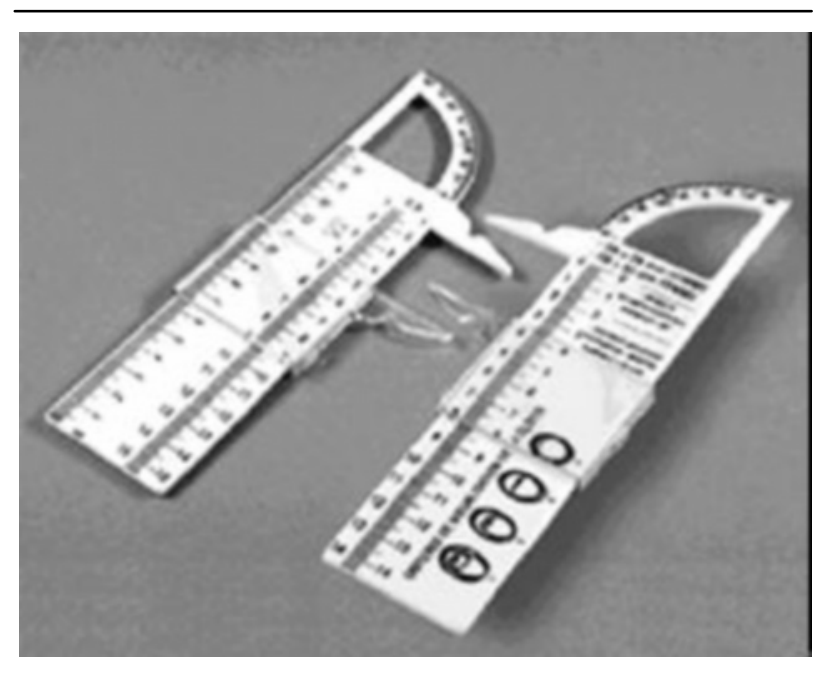

FIGURE Ruler for anesthesiologists to predict intubation difficulties - RAPID. sible may save lives. ${ }^{1-4}$ The existing bedside measurements of: thyromental distance, forward protrusion of the mandible, interincisor gap, atlanto-occipital extension, and the Mallampati test, ${ }^{2}$ have been shown, when taken separately, to be neither sensitive nor specific for routine use. Combinations of various measurements in a multivariate model are being used in the hope of improving the ability to predict (sensitivity and specificity) difficult intubation. ${ }^{5}$ Despite the abundance of literature in this area (more than 1700 manuscripts referenced in the National Library of Medicine), the tools used to measure the relevant criteria are often not described. ${ }^{6}$ How are these measurements taken? Are any investigator-dependent -variables taken into consideration that could influence the validity of these results? ${ }^{7}$

To obviate these difficulties, we use a ruler (Figure) known in France (French patent no. 9103007) as "RAPIDE", an acronym that stands for Réglette d'Anesthésie Prédictive d'une Intubation DifficilE (which could be translated as Ruler for Anesthesiologists to Predict Intubation Difficulties - RAPID). Notched callipers are used to measure the interincisor gap; while pointed callipers are used to measure the thyromental distance and protrusion of the mandible. A half-protractor assists in the measurement of angulations (e.g., atlanto-occipital extension). The Mallampati views are shown for direct comparison. The mean normal values for each sex are presented on the ruler.

In view of limiting inter-investigator variability when measuring the variables used to predict difficulties with intubation, I suggest my colleagues should either obtain the ruler or have one made up. Used in conjunction with precise definitions of the variables to be measured, the "RAPID" ruler will help provide more uniform and reproducible measurements for clinical, teaching and research purposes.

Jean-Pierre Estèbe, MD

Rennes, France

\section{References}

1 Wilson ME. Predicting difficult intubation. Br J Anaesth 1993; 71: 333-4.

2 Mallampati SR, Gatt SP, Gugino LD, et al. A clinical sign to predict difficult intubation: a prospective study. Can Anaesth Soc J 1985; 32: 429-34.

3 Cormack RS, Lehane J. Difficult tracheal intubation in obstetrics. Anaesthesia 1984; 39: 1105-11.

4 Samsoon GL, Young JR Difficult tracheal intubation: a retrospective study. Anaesthesia 1987; 42: 487-90.

5 Rocke DA, Murray WB, Rout CC, Gouws E. Relative 